\title{
Network analysis of DEGs and verification experiments reveal the notable roles of PTTG1 and MMP9 in lung cancer
}

\author{
XIAOHUI XU ${ }^{1,2}$, LEI CAO ${ }^{1,2}$, YE ZHANG $^{1,2}$, YAN YIN $^{1,2}$, XUE HU $^{1,2}$ and YUSHANG CUI ${ }^{1,2}$ \\ ${ }^{1}$ Department of Thoracic Surgery, Peking Union Medical College Hospital; ${ }^{2}$ Graduate School of \\ Peking Union Medical College, Chinese Academy of Medical Sciences, Beijing 100730, P.R. China
}

Received February 1, 2016; Accepted June 2, 2017

DOI: $10.3892 / \mathrm{ol} .2017 .7329$

\begin{abstract}
Lung cancer, a malignant tumor, is the most frequently fatal cancer, with poor survival rates in the advanced stages. In order to improve the understanding of this disease, and to improve the outcomes of patients, additional studies are required. In the present study, differentially expressed genes (DEGs) in patients with lung cancer compared with controls were identified. To understand how these DEGs act together to account for the initiation of lung cancer, a protein interaction network and a transcriptional regulatory network were constructed to explore the clusters and pathways in lung cancer, and the results indicated that PTTG1 and MMP9 served major roles in the development of lung cancer in the regulatory system. Consistent with this, mRNA and protein expression levels of PTTG1 and MMP9 were significantly upregulated in lung cancer tissues compared with normal lung tissues. The overexpression of PTTG1 or MMP9 was induced in the human bronchial epithelial BEAS-2B cell line, indicating that increased PTTG1 or MMP9 alone may not only facilitate cell migration, proliferation and induce colony formation, but also suppress cell apoptosis. In summary, PTTG1 and MMP9 were identified as potential targets for therapeutic intervention through gene therapy in lung cancer.
\end{abstract}

\section{Introduction}

Lung cancer, a malignant tumor, is a common disease with high mortality in China (1). It has been reported that lung cancer is the leading cause of cancer mortality in men aged $\geq 40$ years $(2,3)$. Surgery, chemotherapy and radiotherapy are the primary treatment methods for lung cancer. However, the efficacy of chemotherapy and radiotherapy is limited due to

Correspondence to: Dr Yushang Cui, Department of Thoracic Surgery, Peking Union Medical College Hospital, 1 Shuaifuyuan, Dongcheng, Beijing 100730, P.R. China

E-mail: cys_bj@163.com

Key words: lung cancer, differentially expressed genes, pituitary tumor-transforming gene-1, matrix metalloproteinase 9, human bronchial epithelial BEAS-2B cell line drug resistance, and surgical operation is restricted as a result of local anatomical limitations. The five-year survival rate of lung cancer patients is $\sim 15 \%$ following primary diagnosis (4).

The development of lung cancer may involve the inactivation of tumor suppressor genes, the overexpression of oncogenes or the deregulation of various signaling proteins. Liu et al (5) has suggested that differentially expressed microRNAs in lung cancer compared with the adjacent normal lung tissues may serve tumor suppressive or oncogenic roles. Investigating the alterations in gene expression during tumorigenesis has been demonstrated to serve an important role in the diagnosis of patients with lung cancer, predicting patient survival in early-stage lung adenocarcinomas, and serve as guides for targeted therapies $(6,7)$. Therefore, characterizing the differential expression of functional genes, particularly the known cancer-associated genes, is of great importance, and may provide potential gene-targeted therapies.

Differentially expressed genes (DEGs), identified by the comparison of the gene expression profiles of lung cancer samples with healthy controls, may present a large volume of information for gene-targeted therapies. A previous study performed a microarray analysis to identify the DEGs contributing to radio-resistance in lung cancer cells (8). Another study identified that the network analysis of DEGs revealed key genes in small cell lung cancer (9). The present study aimed to combine the comparative analysis of DEGs between lung cancer and normal tissue with network analysis in the development of lung cancer, to promote the understanding about this disease and to also identify potential targets for diagnostic and therapeutic usage.

In the present study, firstly, an analysis of DEGs in lung cancer tissues was performed, then the protein interaction and transcriptional regulatory networks were identified and analyzed to provide additional insights into the pathogenic mechanism of lung cancer. Pituitary tumor-transforming gene-1 (PTTG1) and matrix metalloproteinase-9 (MMP9) were hypothesized to serve major roles in the development of lung cancer. Secondly, reverse transcription-quantitative polymerase chain reaction (RT-qPCR) and western blotting were performed to verify the expression of these two genes in lung cancer tissues. Finally, the effect of the PTTG1or MMP9 overexpression on migration, proliferation, colony formation and apoptosis in the human bronchial epithelial BEAS-2Bcell line was examined. 


\section{Materials and methods}

Microarray data. Microarray data setsGSE3268 and GSE19804 were downloaded from Gene Expression Omnibus (GEO; https://www.ncbi.nlm.nih.gov/geo/). GSE3268 contains 10 samples, including 5 squamous lung cancer and 5 healthy controls. The annotation information of chip was downloaded from Affymetrix Human Genome U133A Array (http://www.affymetrix.com/support/ technical/manual/expression_manual.affx) (10). GSE19804 contains 120 samples, including 60 lung cancer and 60 healthy controls. The annotation information of chip was downloaded from Affymetrix Human Genome U133 Plus 2.0 Array (http://www.affymetrix.com/support/technical/ manual/expression_manual.affx) (11).

Differential expression analysis. The probe number of the series matrix data was changed to 'gene name'. A gene corresponding to a plurality of probes was taken as the expression average value. As the data was from different platforms, the same data in the two expression profiles was combined. For the combination of two expression profiles, batch error was removed and the datasets were standardized. Then, an expression profile containing 8,172 genes was obtained. The analysis of difference expression was taken by using the Limma package from the Bioconductor project (http://www.bioconductor .org; version 2.7.1) (12). $\mid \log F C l>1$ and $F D R<0.05$ were set as the cut-offs to screen out the differentially expressed genes (DEGs) of the lung cancer-associated genes.

Protein interaction networks and transcriptional regulatory networks. The differentially expressed proteins were analyzed using the Search Tool for the Retrieval of Interacting Genes (STRING) database (https://string-db.org/) to derive protein interaction networks and predict hub proteins (13). The networks between the differentially expressed gene and transcription factors (TFs) in the present study were constructed by using the association between TFs and target genes, which was predicted by University of California Santa Cruz Genome Browser (14).

Patients. A total of 20 patients with lung cancer (with a mean age of $65 \pm 3$ years; 12 male and 8 female) were enrolled from Peking Union Medical College Hospital (Beijing, China) between December 2013 and January 2015. The diagnosis of lung cancer was established using World Health Organization (WHO) morphological criteria (15). Cancerous sample and adjacent non-cancerous lung tissue samples (control) were collected during surgery. Surgically removed samples were stored in liquid nitrogen until use. Written informed consent was obtained from all patients participating in the present study. The present study was approved by the Ethics Committee of Peking Union Medical College Hospital.

Cell and culture. The human bronchial epithelial BEAS-2Bcell line was purchased from the American Type Culture Collection (Manassas, MA, USA). The BEAS-2B cells were cultured in bronchial epithelial cell growth medium (BEGM; Lonza Group, Ltd., Basel, Switzerland) and incubated at $37^{\circ} \mathrm{C}$ in $5 \% \mathrm{CO}_{2}$ as previously described (16).
Plasmid construction and transfection. The DNA fragments of PTTG1 and MMP9 were synthesized by Takara Bio, Inc. (Otsu, Japan). The plasmid pcDNA3.1/V5-His was used to construct expression plasmid pcDNA3.1/V5-His-PTTGland pcDNA3.1/V5-His-MMP9. For the plasmids transfection experiments, BEAS-2Bcells were transfected with pcDNA3.1/V5-His-PTTG1, pcDNA3.1/V5-His-MMP9 and pcDNA3.1/V5-His empty vectors mixed in Lipofectamine ${ }^{\circledR}$ 2000 (Invitrogen; Thermo Fisher Scientific, Inc., Waltham, MA, USA) according to the manufacturer's protocol. Transfection efficiency was evaluated by the percentage of green fluorescent protein-positive cells.

$R T-q P C R$. Total RNA was isolated from lung cancer and healthy lung tissues using TRIzol reagent (Invitrogen; Thermo Fisher Scientific, Inc.). cDNA was prepared by reverse transcription of single-stranded RNA using the High Capacity cDNA Reverse Transcription kit (Applied Biosystems; Thermo Fisher Scientific, Inc.), according to the manufacturer's instructions. Briefly, 1 or $2 \mu \mathrm{g}$ of mRNA, $2 \mu \mathrm{l}$ of RT buffer, $0.8 \mu 1$ of dNTP mixture, $2 \mu 1$ of RT random primers, $1 \mu \mathrm{l}$ of Multi-Scribe reverse transcriptase, and $4.2 \mu \mathrm{l}$ of nuclease-free water were used for each cDNA synthesis. After the reverse transcription, cDNA was stored at $-20^{\circ} \mathrm{C}$. Reactions were incubated in a PCR thermocycler at $25^{\circ} \mathrm{C}$ for $10 \mathrm{~min}, 37^{\circ} \mathrm{C}$ for $120 \mathrm{~min}$, and $85^{\circ} \mathrm{C}$ for $5 \mathrm{~min}$ and then cooled to $4^{\circ} \mathrm{C}$. RT-qPCR was carried out using the $\mathrm{SYBR}^{\circledR}$ Premix Ex Taq ${ }^{\mathrm{TM}}$ kit (Takara Bio, Inc., Otsu, Japan), according to the manufacturer's instructions. The $20 \mathrm{ml}$ reaction mix consisted of $2 \mathrm{ml} 30$-fold diluted 1st-strand cDNA, $10 \mathrm{ml} 2 \mathrm{X} \mathrm{SYBR}{ }^{\circledR}$ Premix Ex Taq ${ }^{\mathrm{TM}}, 0.4 \mathrm{ml} 10 \mathrm{mM}$ forward and reverse primer, $0.4 \mathrm{ml}$ 50X ROX Reference Dye and $6.8 \mathrm{ml}$ DEPC-treated water. The primer pairs used in these reactions were as follows: PTTG1forward, 5'-TGATCCTTGACGAGGAGAGAG-3' and reverse, 5'-GGTGGCAATTCAACATCCAGG-3'; MMP9, forward, 5'-GGGCCGCTCCTACTCTGCCT-3' and reverse, 5'-TCGAGTCAGCTCGGGTCGGG-3'; GAPDH, forward, 5'-GAAGGTGAAGGTCGGAGTC-3' and reverse, 5'-GAA GATGGTGATGGGATTC-3'. Reactions were performed in an ABI7300 Real-Time quantitative instrument (Applied Biosystems; Thermo Fisher Scientific, Inc.). The thermocycling conditions were as follows: Initial denaturation at $95^{\circ} \mathrm{C}$ for $30 \mathrm{sec}$, followed by 40 cycles of $95^{\circ} \mathrm{C}$ for $5 \mathrm{sec}$ and $60^{\circ} \mathrm{C}$ for $31 \mathrm{sec}$. The expression level of the internal control gene GAPDH, was used as a housekeeping gene, and the comparative $2^{-\Delta \Delta C q}$ method (17) was used to quantify gene expression levels. All experiments were performed in triplicate.

Western blot analysis. Protein was collected from lung cancer tissues and normal tissues that were lysed in radioimmunoprecipitation assay (RIPA) buffer containing protease inhibitors at $4^{\circ} \mathrm{C}$ for $30 \mathrm{~min}$. Cell lysates were prepared with a RIPA lysis buffer kit (Santa Cruz Biotechnology, Inc., Dallas, TX, USA), and the protein concentrations were quantified using a Bio-Rad protein assay using the Bradford method (Bio-Rad Laboratories, Inc., Hercules, CA, USA). Proteins (30 $\mu \mathrm{g}$ per lane) were separated on $8 \%$ SDS-PAGE and transferred to polyvinylidene difluoride membranes (Amersham; GE Healthcare, Chicago, IL, USA). The membranes were blocked in $5 \%$ non-fat milk overnight at $4^{\circ} \mathrm{C}$. Transferred membranes 


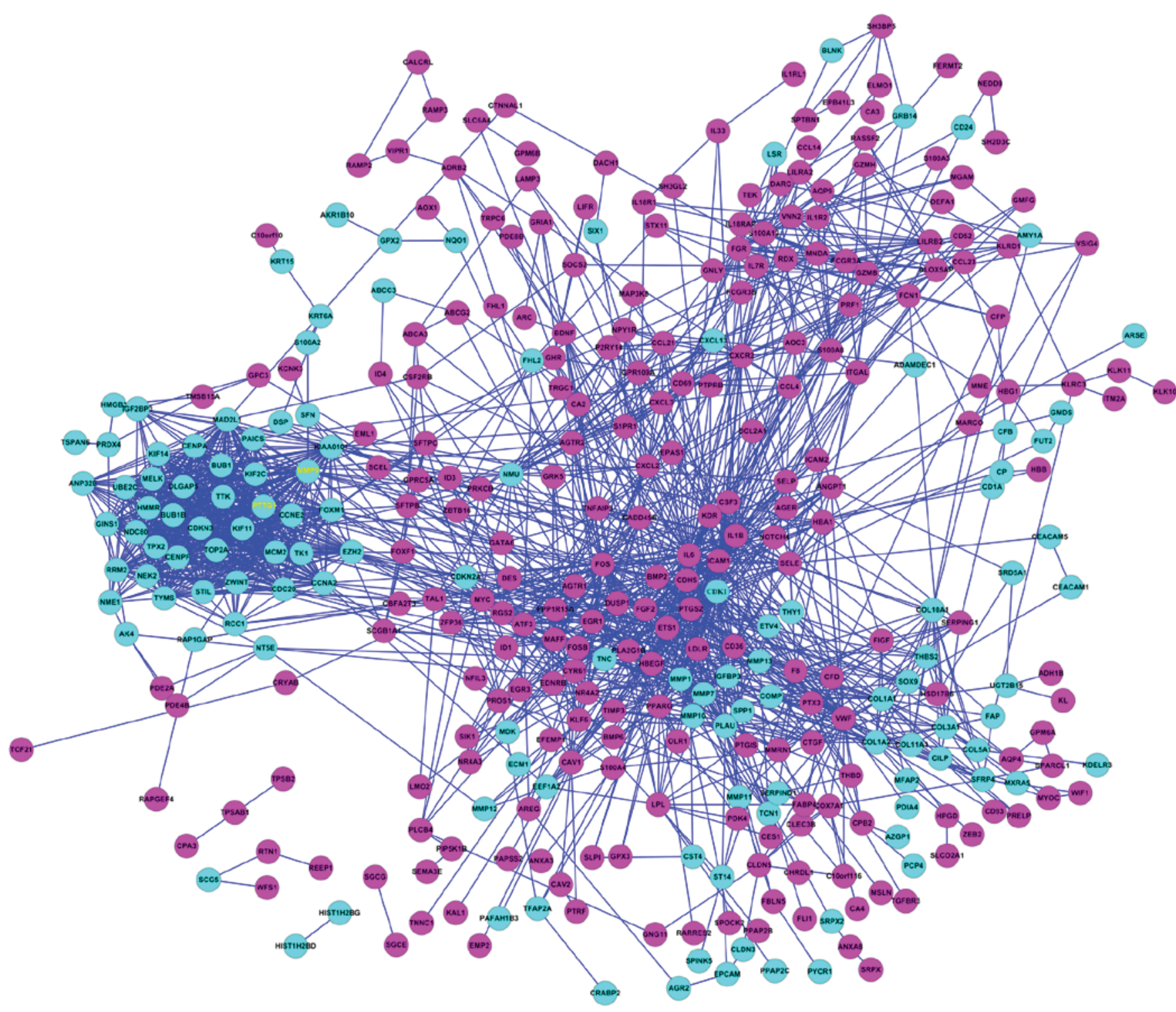

Figure 1. Protein interaction networks for differentially expressed proteins. Pink circles represent downregulated genes and blue circles represent upregulated genes. PTTG1 and MMP9 are highlighted in yellow fonts. PTTG1, pituitary tumor-transforming gene-1; MMP9, matrix metalloproteinase 9.

were then stained with the following primary antibodies: anti-PTTG1 (1:500; cat. no. 341500; Invitrogen; Thermo Fisher Scientific, Inc.), anti-MMP9 (1:500; cat. no. ab76003; Abcam, Cambridge, MA, USA) and anti-GAPDH (1:500; cat. no. ab8245; Santa Cruz Biotechnology, Inc.) overnight at $4^{\circ} \mathrm{C}$. Subsequently, protein bands were detected by incubation with a horseradish peroxidase-conjugated secondary antibody (1:1,000; Origene Technologies, Inc., Beijing, China; cat. no. A50-106P) at room temperature for $1 \mathrm{~h}$. Signals were detected using an enhanced chemiluminescence kit (Wuhan Boster Biological Technology Co., Ltd., Wuhan, China; cat. no. orb90504) and exposed to Kodak X-OMAT film (Kodak, Rochester, NY, USA). Each experiment was performed at least three times and the results were analyzed using Alpha View Analysis Tools [AlphaView (SA) software version 3.2.2; Protein Simple, San Jose, CA, USA].

Transwell assay. BEAS-2B cells with pcDNA3.1/ V5-His-PTTG1, pcDNA3.1/V5-His-MMP9 and pcDNA3.1/
V5-His empty vectors were serum-starved overnight and resuspended in serum-free medium. A total of $300 \mu \mathrm{l}$ cell suspension was placed in the upper Transwell insert with Matrigel (BD Biosciences, Franklin Lakes, NJ, USA). The chambers were placed in 24-well plates and cultured in $700 \mu \mathrm{l}$ BEGM medium with $25 \%$ fetal bovine serum (Gibco; Thermo Fisher Scientific, Inc.) to allow the cells to migrate through the porous membrane for $24 \mathrm{~h}$ at $37^{\circ} \mathrm{C}$. The cells adhered to the lower surface were fixed with $100 \%$ methanol for $20 \mathrm{~min}$ at room temperature and stained with 5\% Giemsa solution (Merck \& Co., Inc., Whitehouse Station, NJ, USA) for $20 \mathrm{~min}$ at room temperature. The total number of cells on the lower surface of the membrane was counted by light microscopy using five random fields (BX50; Olympus Corporation, Tokyo, Japan; magnification, x100).

Cell proliferation assay. Cell proliferation was assessed by a CCK-8 kit (Wuhan Boster Biological Technology, Ltd., Wuhan, China). Briefly, the WST-8 was added to the culture medium, 


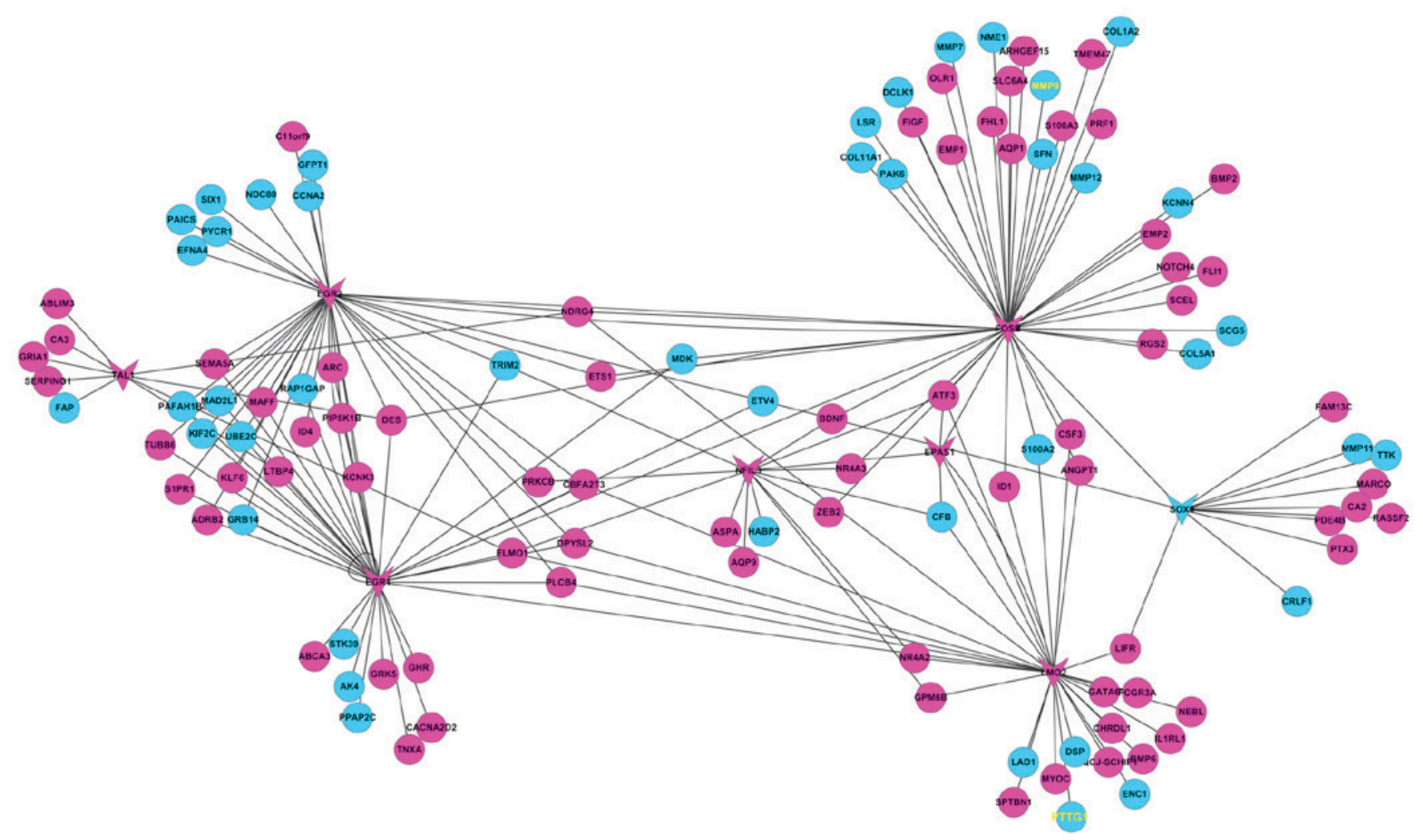

Figure 2. Transcription factor regulatory networks. Blue and pink arrows represent transcription factors; blue figures represent upregulated genes and pink figures represent downregulated genes. PTTG1 and MMP9 are highlighted in yellow fonts. PTTG1, pituitary tumor-transforming gene-1; MMP9, matrix metalloproteinase 9 .

and the cultures were incubated for $1 \mathrm{~h}$ at $37^{\circ} \mathrm{C}$ in $5 \% \mathrm{CO}_{2}$. The absorbance was measured at $450 \mathrm{~nm}$ using a Microplate Reader (Bio-Rad Laboratories, Inc., Hercules, CA, USA).

Colony formation assay. Tumor cells were seeded at a density of 300 cells $/ \mathrm{ml}$ on $35-\mathrm{mm}$ dishes. The colony formation assay was performed as previously described (18).

Apoptosis assay. An Annexin V-fluorescein isothiocyanate (FITC) staining assay (Invitrogen; Thermo Fisher Scientific, Inc.) was performed according to the protocol of the manufacturer to quantify cell apoptosis. Briefly, the cells were harvested and stained with $3 \mu \mathrm{l}$ Annexin V-FITC $(25 \mu \mathrm{g} / \mathrm{ml})$ and $5 \mu \mathrm{l}$ propidium iodide $(50 \mu \mathrm{g} / \mathrm{ml})$ for $20 \mathrm{~min}$ at $37^{\circ} \mathrm{C}$. Then, the cells were washed twice with PBS, and the fluorescence was analyzed using a FACSCalibur flow cytometry system (BD Biosciences).

Statistical analysis. The unpaired t-test was used for comparisons between two groups. A one-way analysis of variance followed by a Tukey's test was used to compare multiple groups. The software SPSS 13.0 (SPSS, Inc., Chicago, IL, USA) was used to analyze all these data. ${ }^{*} \mathrm{P}<0.05,{ }^{* *} \mathrm{P}<0.01$ and ${ }^{* * *} \mathrm{P}<0.001$ vs. control. The data were expressed as mean \pm standard error of the mean.

\section{Results}

Selection of DEGs. The same data in GSE3268 and GSE19804was combined. For the combination of the two expression profiles, batch error was removed and the datasets were standardized. Then, the differential expression of the genes was analyzed using Limma package. Following calculation of the data using the standardized approach, a total of 466 difference expression genes were screened, including 310 downregulated genes (Fig. 1, blue circles) and 156 upregulated genes (Fig. 1, pink circles).

Constructing the protein interaction networks. Protein interaction networks corresponding with the DEGs were constructed using the STRING online tools. The results demonstrated that the degree of certain nodes was markedly higher compared with the average degree in the networks (Fig. 1). The genes with significantly higher degrees were PTTG1 and MMP9 (yellow font).

Constructing the transcription factor regulatory networks. Then, transcription factor regulatory networks were constructed subsequent to select the transcription factors of the DEGs (Fig. 2). The results demonstrated that PTTG1 appeared to be regulated by $\mathrm{LMO} 2$, a molecule associated with cancer cell growth and differentiation $(19,20)$. In addition, MMP9 was predicted to be regulated by FBJ murine osteosarcoma viral oncogene homolog B, a tumorigenesis-associated protein $(21,22)$. Taken together, PTTG1 and MMP9 appear to be potential key genes in the onset and development of lung cancer.

PTTG1 and MMP9 are upregulated in lung cancer tissues. To determine the role of PTTG1 and MMP9 in lung cancer, firstly, 

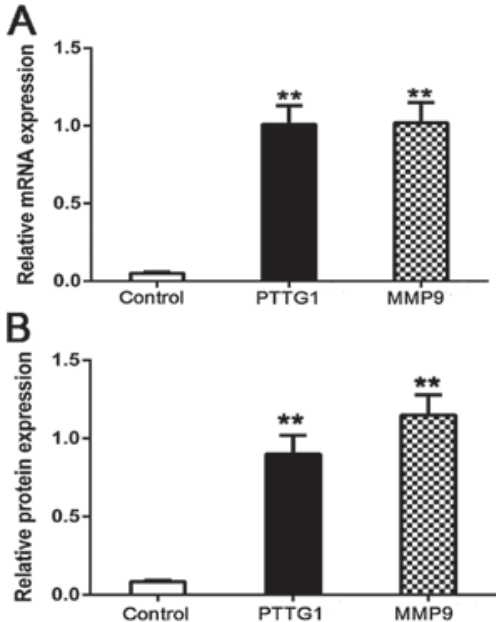

Figure 3. PT-PCR and western blotting of PTTG1 and MMP9. (A) The mRNA expression levels of PTTG1 and MMP9 in lung cancer and healthy lung tissues. (B) The protein expression levels of PTTG1 and MMP9 in lung cancer and healthy lung tissues. Data are presented as the mean \pm standard deviation of four independent experiments. ${ }^{* *} \mathrm{P}<0.01$ compared with the control.

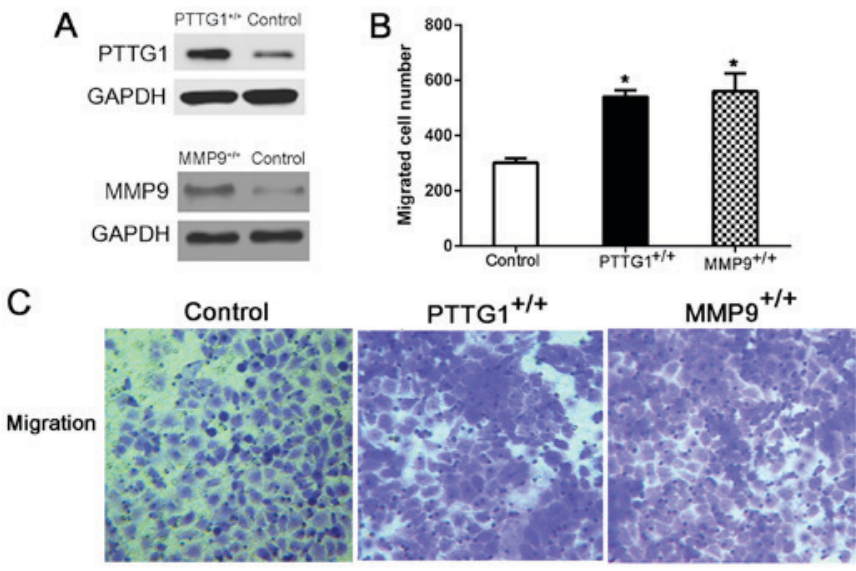

Figure 4. Effects of overexpression of PTTG1or MMP9 on migration in BEAS-2B cells. (A) The protein expression levels of PTTG1 or MMP9 in BEAS-2B cells transfected with pcDNA3.1/V5-His-PTTG1and pcDNA3.1/V5-His-MMP9 vectors. (B) The statistical results of the Transwell migration assay. Data are presented as the mean \pm standard deviation of four independent experiments. ${ }^{*} \mathrm{P}<0.05$. (C) Transwell migration assay demonstrated that BEAS-2B cells transfected with the PTTG1or MMP9 vectors exhibited higher migratory rates compared with the control through microscopy (magnification, x100). PTTG1, pituitary tumor-transforming gene-1; MMP9, matrix metalloproteinase 9. ${ }^{.} \mathrm{P}<0.05$ compared with the control.

the mRNA and protein expression of PTTG1 and MMP9 in 20 patients with lung cancer and 10 healthy lung tissues were detected by RT-qPCR and western blot. The results indicated that the mRNA level expressions of PTTG1 and MMP9 were significantly upregulated compared with the control $(\mathrm{P}<0.01$; Fig. 3A). Similarly, the protein level expression of PTTG1 and MMP9 were significantly increased compared with the control $(\mathrm{P}<0.01$; Fig. 3B). These investigations were consistent with analysis of networks (Figs. 1 and 2).

PTTG1 and MMP9 facilitate migration and proliferation, increase colony formation and suppress apoptosis in $B E A S-2 B$ cells. As cancer cell migration, proliferation, colony
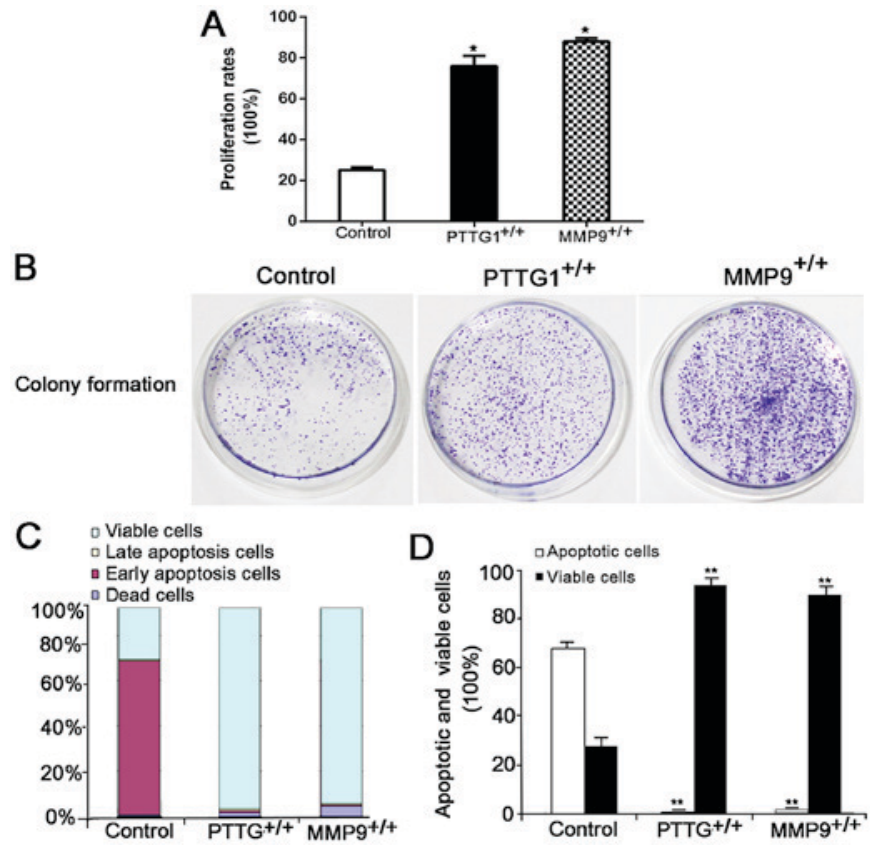

Figure 5. Effects of overexpression of PTTG1or MMP9 on proliferation, colony formation and apoptosis in BEAS-2B cells. (A) BEAS-2B cells transfected with the PTTG1or MMP9 vectors exhibited higher proliferative rates compared with the control. (B) BEAS-2B cells transfected with the PTTGlor MMP9 vectors promoted colony formation compared with the control. (C) The statistical results of viable, early apoptotic, late apoptotic and dead cells in control, $\mathrm{PTTG1}^{+/+}$and $\mathrm{MMP}^{+/+}$groups. (D) BEAS-2B cells transfected with the PTTG1or MMP9 vectors exhibited lower apoptotic rates compared with the control. Data are presented as the mean \pm standard deviation of four independent experiments. ${ }^{*} \mathrm{P}<0.05,{ }^{* *} \mathrm{P}<0.01$ compared with the control.

formation and apoptosis are closely associated with tumorigenesis (23), BEAS-2B cells with pcDNA3.1/V5-His-PTTG1 and pcDNA3.1/V5-His-MMP9 were successful constructed to explore the role of PTTG1 and MMP9 in lung cancer tumorigenesis (Fig. 4A). Firstly, the Transwell assay demonstrated that the overexpression of PTTG1 $\left(\mathrm{PTTG}^{+++}\right)$or MMP9 $\left(\mathrm{MMP9}^{+/+}\right)$significantly increased the migration of BEAS-2B cells (both $\mathrm{P}<0.05$; Fig. 4B and C). Then, the results of CCK-8 assay indicated that the overexpression of PTTG1 or MMP9 significantly increased the proliferation ability of BEAS-2B cells (both $\mathrm{P}<0.05$; Fig. 5A). PTTG1 or MMP9 markedly induced colony formation ability compared with the control (Fig. 5B). Finally, the results of apoptosis assay suggested that the overexpression of PTTG1or MMP9 significantly suppressed the apoptosis of BEAS-2B cells (Fig. 5C and D). In summary, PTTG1 and MMP9 may facilitate the migration and proliferation, induce colony formation and suppress apoptosis of BEAS-2B cells, suggesting the vital roles of PTTG1 and MMP9 in promoting lung cancer development.

\section{Discussion}

Lung cancer is a common disease with high mortality in China (1). It is fatal, and possesses a varied epidemiology on the basis of sex, geographical regions and age (3). In the present study, DEGs associated with the biogenesis of lung cancer were screened. Then, the protein interaction and transcriptional regulatory networks of lung cancer were analyzed. PTTG1 and MMP9 genes were hypothesized to 
serve major roles in the development of lung cancer based on the network analysis. Additional analysis was performed to improve the understanding of the biological implications of these two genes, and the results demonstrated that the tumorigenic roles of PTTG1 and MMP9 were to promote migration and proliferation, induce colony formation and suppress apoptosis.

PTTG1 was primarily isolated from rat pituitary tumor cells (24). Subsequently, PTTG1, a vertebrate securin, was identified to exert its effects on cell cycle control, cell replication, organ development, metabolism, DNA damage/repair, cell transformation and cell senescence $(25,26)$. Notably, PTTG1 is highly expressed in a variety of organs, including colon, pituitary, thyroid, breast, ovary, uterine and esophagus, particularly in the lungs (27-33). Consistent with the present study, PTTG1 has been indicated to be a key signature gene associated with tumor metastasis (25,34-36). The mechanism is complex: PTTG1 exhibits the ability to activate c-Myc and cyclin D3, increase basic fibroblast growth factor, vascular endothelial growth factor and matrix metalloproteinase 2 expression to induce angiogenesis, and also induce interleukin-8 to function in metastasis (25,34-36). PTTG1 may also interact with transcription factors including tumor protein 53 , transcription factor Sp1 and upstream stimulatory factor 1 , which were reported to be involved in tumorigenesis and cancer development $(34,37,38)$.

MMP-9 (also known as gelatinase-B), a 92-kDa gelatinase, catalyzes type IV collagen in the basal membrane and is considered as a key enzyme (39). It serves an important role in regulating tumor cell behaviors, including growth, differentiation, apoptosis, migration, invasion, tumor angiogenesis, and immune surveillance $(40,41)$. The expression of MMP-9 was reported to be significantly higher in non-small cell lung cancer and small cell lung cancer compared with normal tissues, and also associated with pathological type and prognosis (42). The underlying mechanism of the carcinogenic role of MMP-9 is also complex and requires additional precise investigation $(43,44)$.

Overall, the present study demonstrated that PTTG1 and MMP9 were key signature genes associated with tumorigenesis. Mechanically, increased PTTG1 or MMP9 may facilitate cell migration and proliferation, induce colony formation and suppress cell apoptosis. The present study also suggested that PTTG and MMP9 may serve as important target genes for the treatment of lung cancer. The molecular mechanism by which PTTG and MMP9 mediates their tumorigenic function in this study remain intricate.

\section{References}

1. Zhou LF, Zhang MX, Kong LQ, Lyman GH, Wang K, Lu W, Feng QM, Wei B and Zhao LP: Costs, trends and related factors in treating lung cancer patients in 67 hospitals in Guangxi, China. Cancer Invest 35: 345-357, 2017.

2. Siegel R, Ma J, Zou Z and Jemal A: Cancer statistics, 2014. CA Cancer J Clin 64: 9-29, 2014.

3. Sachdeva M, Sachdeva N, Pal M, Gupta N, Khan IA, Majumdar M and Tiwari A: CRISPR/Cas9: Molecular tool for gene therapy to target genome and epigenome in the treatment of lung cancer. Cancer Gene Ther 22: 509-517, 2015.

4. Reddy C, Chilla D and Boltax J: Lung cancer screening: A review of available data and current guidelines. Hosp Pract (1995) 39: 107-112, 2011.
5. Liu X, Sempere LF, Guo Y, Korc M, Kauppinen S, Freemantle SJ and Dmitrovsky E: Involvement of MicroRNAs in lung cancer biology and therapy. Transl Res 157: 200-208, 2011.

6. Bhattacharjee A, Richards WG, Staunton J, Li C, Monti S, Vasa P, Ladd C, Beheshti J, Bueno R, Gillette M, et al: Classification of human lung carcinomas by mRNA expression profiling reveals distinct adenocarcinoma subclasses. Proc Natl Acad Sci USA 98: 13790-13795, 2001.

7. Beer DG, Kardia SL, Huang CC, Giordano TJ, Levin AM, Misek DE, Lin L, Chen G, Gharib TG, Thomas DG, et al: Gene-expression profiles predict survival of patients with lung adenocarcinoma. Nat Med 8: 816-824, 2002.

8. Guo WF, Lin RX, Huang J, Zhou Z, Yang J, Guo GZ and Wang SQ: Identification of differentially expressed genes contributing to radioresistance in lung cancer cells using microarray analysis. Radiat Res 164: 27-35, 2005.

9. Tantai JC, Pan XF and Zhao H: Network analysis of differentially expressed genes reveals key genes in small cell lung cancer. Eur Rev Med Pharmacol Sci 19: 1364-1372, 2015.

10. Wachi S, Yoneda K and Wu R: Interactome-transcriptome analysis reveals the high centrality of genes differentially expressed in lung cancer tissues. Bioinformatics 21: 4205-4208, 2005.

11. Lv M and Wang L: Comprehensive analysis of genes, pathways, and TFs in nonsmoking Taiwan females with lung cancer. Exp Lung Res 41: 74-83, 2015.

12. Ritchie ME, Phipson B, Wu D, Hu Y, Law CW, Shi W and Smyth GK: Limma powers differential expression analyses for RNA-sequencing and microarray studies. Nucleic Acids Res 43: e47, 2015.

13. Hsia CW, Ho MY, Shui HA, Tsai CB and Tseng MJ: Analysis of dermal papilla cell interactome using STRING database to profile the ex vivo hair growth inhibition effect of a vinca alkaloid drug, colchicine. Int J Mol Sci 16: 3579-3598, 2015.

14. Jenjaroenpun $P$ and Kuznetsov VA: TTS mapping: Integrative WEB tool for analysis of triplex formation target DNA sequences, G-quadruplets and non-protein coding regulatory DNA elements in the human genome. BMC Genomics 10 (Suppl 3): S9, 2009.

15. Yesner R and Matthews MJ: World health organization lung cancer classification: pathology of lung cancer. Chest 89 (Suppl): 315S, 1986.

16. Hudy MH, Traves SL, Wiehler S and Proud D: Cigarette smoke modulates rhinovirus-induced airway epithelial cell chemokine production. Eur Respir J 35: 1256-1263, 2010.

17. Livak KJ and Schmittgen TD: Analysis of relative gene expression data using real-time quantitative PCR and the 2(-Delta Delta C(T)) method. Methods 25: 402-408, 2001.

18. Zheng L, Jiang G, Mei H, Pu J, Dong J, Hou X and Tong Q: Small RNA interference-mediated gene silencing of heparanase abolishes the invasion, metastasis and angiogenesis of gastric cancer cells. BMC Cancer 10: 33, 2010.

19. McCormack MP, Young LF, Vasudevan S, de Graaf CA, Codrington R, Rabbitts TH, Jane SM and Curtis DJ: The Lmo2 oncogene initiates leukemia in mice by inducing thymocyte self-renewal. Science 327: 879-883, 2010.

20. Yamada Y, Pannell R, Forster A and Rabbitts TH: The LIM-domain protein $\mathrm{Lmo} 2$ is a key regulator of tumour angiogenesis: A new anti-angiogenesis drug target. Oncogene 21: 1309-1315, 2002.

21. Han SA, Song JY, Min SY, Park WS, Kim MJ, Chung JH and Kwon KH: A genetic association analysis of polymorphisms, rs2282695 and rs12373539, in the FOSB gene and papillary thyroid cancer. Exp Ther Med 4: 519-523, 2012.

22. Shahzad MM, Arevalo JM, Armaiz-Pena GN, Lu C, Stone RL, Moreno-Smith M, Nishimura M, Lee JW, Jennings NB, Bottsford-Miller J, et al: Stress effects on FosB- and interleukin-8 (IL8)-driven ovarian cancer growth and metastasis. J Biol Chem 285: 35462-35470, 2010.

23. Vella LJ: The emerging role of exosomes in epithelial-mesenchymal-transition in cancer. Front Oncol 4: 361, 2014.

24. Pei L and Melmed S: Isolation and characterization of a pituitary tumor-transforming gene (PTTG). Mol Endocrinol 11: 433-441, 1997.

25. Smith VE, Franklyn JA and McCabe CJ: Pituitary tumor-transforming gene and its binding factor in endocrine cancer. Expert Rev Mol Med 12: e38, 2010.

26. Salehi F, Kovacs K, Scheithauer BW, Lloyd RV and Cusimano M: Pituitary tumor-transforming gene in endocrine and other neoplasms: A review and update. Endocr Relat Cancer 15: 721-743, 2008. 
27. Yasuyuki S, Nobuhiro H, Yoshiyuki K, Nishiwaki T, Kato J, Shinoda N, Sato A, Kimura M, Koyama H, Toyama T, et al: Expression of PTTG (pituitary tumor transforming gene) in esophageal cancer. Jpn J Clin Oncol 32: 233-237, 2002.

28. Xin DQ, Zhu XH, Lai YQ, You R, Na YQ, Guo YL and Mao ZB: Regulation of expression of pituitary tumor transforming gene 1 (PTTG1) by androgen in prostate cancer. Beijing Da Xue Xue Bao 37: 638-640, 2005 (In Chinese)

29. Mu YM, Oba K, Yanase T, Ito T, Ashida K, Goto K, Morinaga H, Ikuyama S, Takayanagi R and Nawata H: Human pituitary tumor transforming gene (hPTTG) inhibits human lung cancer A549 cell growth through activation of p21 (WAF1/CIP1). Endocr J 50: 771-781, 2003 .

30. Chen CC, Chang TW, Chen FM, Hou MF, Hung SY, Chong IW, Lee SC, Zhou TH and Lin SR: Combination of multiple mRNA markers (PTTG1, Survivin, UbcH10 and TK1) in the diagnosis of Taiwanese patients with breast cancer by membrane array. Oncology 70: 438-446, 2006

31. Kim DS, Franklyn JA, Stratford AL, Boelaert K, Watkinson JC, Eggo MC and McCabe CJ: Pituitary tumor-transforming gene regulates multiple downstream angiogenic genes in thyroid cancer. J Clin Endocrinol Metab 91: 1119-1128, 2006.

32. Kim JW, Song JY, Lee JM, Lee JK, Lee NW, Yeom BW and Lee KW: Expression of pituitary tumor-transforming gene in endometrial cancer as a prognostic marker. Int J Gynecol Cancer 18: 1352-1359, 2008.

33. Yoon CH, Kim MJ, Lee H, Kim RK, Lim EJ, Yoo KC, Lee GH, Cui YH, Oh YS, Gye MC, et al: PTTG1 oncogene promotes tumor malignancy via epithelial to mesenchymal transition and expansion of cancer stem cell population. J Biol Chem 287: 19516-19527, 2012.

34. Lewy GD, Ryan GA, Read ML, Fong JC, Poole V, Seed RI, Sharma N, Smith VE, Kwan PP, Stewart SL, et al: Regulation of pituitary tumor transforming gene (PTTG) expression and phosphorylation in thyroid cells. Endocrinology 154: 4408-4422, 2013.

35. McCabe CJ, Khaira JS, Boelaert K, Heaney AP, Tannahill LA, Hussain S, Mitchell R, Olliff J, Sheppard MC, Franklyn JA and Gittoes NJ: Expression of pituitary tumour transforming gene (PTTG) and fibroblast growth factor-2 (FGF-2) in human pituitary adenomas: Relationships to clinical tumour behaviour. Clin Endocrinol (Oxf) 58: 141-150, 2003
36. Malik MT and Kakar SS: Regulation of angiogenesis and invasion by human Pituitary tumor transforming gene (PTTG) through increased expression and secretion of matrix metalloproteinase-2 (MMP-2). Mol Cancer 5: 61, 2006.

37. Hamid T and Kakar SS: PTTG/securin activates expression of p53 and modulates its function. Mol Cancer 3: 18, 2004

38. Cho-Rok J, Yoo J, Jang YJ, Kim S, Chu IS, Yeom YI, Choi JY and Im DS: Adenovirus-mediated transfer of siRNA against PTTG1 inhibits liver cancer cell growth in vitro and in vivo. Hepatology 43: 1042-1052, 2006.

39. Chirco R, Liu XW, Jung KK and Kim HR: Novel functions of TIMPs in cell signaling. Cancer Metastasis Rev 25: 99-113, 2006.

40. Sheu BC, Hsu SM, Ho HN, Lien HC, Huang SC and Lin RH: A novel role of metalloproteinase in cancer-mediated immunosuppression. Cancer Res 61: 237-242, 2001.

41. Bergers G, Brekken R, Mcmahon G, Vu TH, Itoh T, Tamaki K, Tanzawa K, Thorpe P, Itohara S, Werb Z and Hanahan D: Matrix metalloproteinase-9 triggers the angiogenic switch during carcinogenesis. Nat Cell Biol 2: 737-744, 2000.

42. El-Badrawy MK, Yousef AM, Shaalan D and Elsamanoudy AZ: Matrix metalloproteinase-9 expression in lung cancer patients and its relation to serum mmp-9 activity, pathologic type, and prognosis. J Bronchology Interv Pulmonol 21: 327-334, 2014.

43. Cheng X, Yang Y, Fan Z, Yu L, Bai H, Zhou B, Wu X, Xu H, Fang M, Shen A, et al: MKL1 potentiates lung cancer cell migration and invasion by epigenetically activating MMP9 transcription. Oncogene 34: 5570-5581, 2015.

44. Li L, Tan J, Zhang Y, Han N, Di X, Xiao T, Cheng S, Gao Y and Liu Y: DLK1 promotes lung cancer cell invasion through upregulation of MMP9 expression depending on notch signaling. PLoS One 9: e91509, 2014.

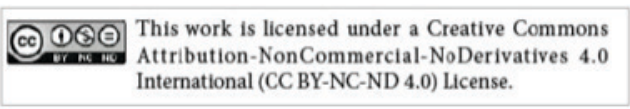

